\title{
Uma trama de fios interculturais: considerações sobre 0 legado do Projeto Magdalena
}

\author{
A woof made of intercultural threads: \\ Considerations about the legacy of the Magdalena Project
}

por Marisa de Souza Naspolini

\begin{abstract}
RESUMO
Este artigo tece algumas considerações acerca do legado constituído pelos 25 anos de atividades do Projeto Magdalena - rede internacional de mulheres de teatro presente em mais de 50 países, que tem contribuído significativamente para dar visibilidade ao trabaIho feito por mulheres no campo teatral. Trata-se de uma organização de características fortemente colaborativas baseada em uma estrutura horizontal, não-hierárquica, constituída por artistas que buscam compartilhar e aprimorar sua criação artística. Os principais aspectos levantados estão ligados à forma de organização em rede e à abordagem intercultural presente no projeto. Além de pesquisa bibliográfica, a autora realizou entrevistas e participou de eventos ligados à rede, obtendo depoimentos pessoais voltados para os temas em questão. Este artigo é parte de uma pesquisa de maior porte que busca investigar experiências interculturais como parte do processo criativo de artistas ligadas à Rede Magdalena.
\end{abstract}

Palavras-chave Projeto Magdalena; Rede; Interculturalidade

\section{ABSTRACT}

This article makes considerations about the legacy of the 25 years of the Magdalena Project - international network of women in theatre now present in more than 50 countries around the world. This network has contributed in a very relevant way to bring visibility to work made by women in theatre. It is a collaborative organization based on a horizontal structure, non hierarchical, constituted by artists that are searching for sharing and improving their artistic creation. The main aspects presented are connected to the network organization and the intercultural approach present in the project. Besides bibliographical research, the author has made interviews and participated in many events connected to the network. This article is part of a larger research that aims to investigate intercultural experiences as part of creative processes inside The Magdalena Project.

Keywords The Magdalena Project; Network; Intercultural 
O Projeto Magdalena (The Magdalena Project) é uma rede dinâmica de mulheres de teatro, de caráter multicultural, que surgiu como um espaço de discussão, troca e apoio mútuo visando gerar visibilidade ao trabalho artístico de mulheres. Através da rede, praticantes de teatro de todo o mundo, sejam companhias, artistas individuais ou acadêmicas, encontraram um espaço crítico de reconhecimento do seu trabalho. Criado em 1986 no País de Gales, por um grupo de 36 mulheres coordenado pela diretora galesa jill Greenhalgh, o Projeto comemorou 25 anos em agosto de 2011 e se sedimentou como uma organização autônoma, com características de auto-seleção', hoje presente em mais de 50 países e em constante transformação e crescimento.

0 Projeto pode ser identificado a partir de várias de suas atividades, como festivais, encontros, conferências, workshops, processos de criação colaborativos, documentários, livros, filmes, publicações periódicas e um fórum virtual, entre outras, mas sua essência transcende em muito a soma de suas partes. Para Susan Bassnett, autora do livro Magdalena - International Women's Experimental Theatre, o primeiro dedicado ao tema, o Projeto Magdalena é caracterizado fundamentalmente pela fluidez: "não a fluidez de uma massa solta amorfa, mas uma fluidez que é um poder móvel que aumenta e diminui de acordo com o poder psíquico do indivíduo e tem sido uma pedra fundamental na criatividade e no pensamento feminista" (BASSNETT apud FRY, 2007, p. 13, trad. nossa).

Desde a sua fundação, como um espaço original - e único - de troca e compartiIhamento de metodologias e práticas em constante aprimoramento e atualização, o projeto se revelou entrelaçado com a perspectiva da interculturalidade, através de encontros, festivais e publicações que procuram estimular a experiência de mulheres de diferentes culturas. Tanto quanto no caráter da rede como um todo, que se apóia na pluralidade e no diálogo, podemos encontrar na prática de suas integrantes, individualmente, aspectos ligados ao hibridismo e à ocupação de territórios fronteiriços. Trata-se, sobretudo, de um espaço de investigação que se reporta a diferentes tradições cênicas e culturais para gerar um ambiente fértil na construção de novas poéticas teatrais. As centenas de eventos já realizados nos seus 25 anos de existência trazem no âmago a necessidade e o desejo de reconhecimento do outro.

De acordo com jill Greenhalgh, fundadora do Projeto, suas estratégias de organização e sobrevivência estão alicerçadas em uma estrutura horizontal, "um truque de cooperação, como sugere Germaine Greer" ${ }^{2 \prime}$ que, desde o início, busca uma ação

\footnotetext{
1 Segundo Greenhalgh, não há convite ou forma de seleção para integrar o projeto. Se uma artista quiser se envolver com o Projeto Magdalena, deve optar por isso e assumir responsabilidades. Cada mulher deve encontrar sua própria forma de participar da rede, buscando sempre um sentido pessoal, uma necessidade que é primeiramente pertencente à esfera do indivíduo. (GREENHALGH, palestra proferida em Guanajuato, México, em 17 jul. 2011).
}

2 Germaine Greer, em frase famosa, declarou: "I do think that women could make politics 
cooperativa que se desvie de padrões hierárquicos verticais, de características fortemente patriarcais, para inventar/construir novas regras de organização que sejam adequadas para essa comunidade específica (GREENHALGH, 2008).

A rede, por definição, propõe-se ao diálogo e ao confronto construtivo, privilegiando uma visão cultural não hegemônica e apostando na integração das diferenças. A horizontalidade a que se refere Greenhalgh é uma característica própria das organizações em rede, em contraposição à estrutura piramidal, e é em parte o que as define. Segundo Francisco Whitaker, membro brasileiro do comitê gestor do Fórum Social Mundial, neste tipo de estrutura seus integrantes se ligam horizontalmente aos demais, resultando em uma malha de múltiplos fios, que pode se espalhar indefinidamente sem que nenhum de seus nós seja considerado principal ou central. Em uma rede, todos os integrantes são sujeitos autônomos que participam por motivação própria, não por obrigação ou hierarquia. 0 importante da rede é a distribuição de responsabilidades. Mais do que a presença de um "chefe", há um desejo coletivo de realizar um objetivo comum (WHITAKER, 1993).

A organização em rede não pode ser imposta como modelo organizacional de cima para baixo. Para ser legítima, sua construção deve surgir de um desejo de participação coletivo. Assim, segundo Cássio Martinho, "o 'modelo' emerge como decorrência de uma interconexão de entes autônomos e que preservam sua autonomia" (MARTINHO, 2002, p. 3). Ao final do encontro realizado em 1986, no País de Gales, que deu início ao Projeto Magdalena, as próprias participantes deixaram claro 0 seu desejo - e necessidade - de continuidade. Desde então, passados 25 anos, as células constituintes da rede se multiplicaram, criaram novas articulações, ampliaram o fluxo de conexões, fortaleceram-se reciprocamente, fortalecendo assim o próprio conjunto.

0 sociólogo espanhol Manuel Castells define rede como "um conjunto de nós interconectados". Cada nódulo da rede representaria uma unidade e cada fio um canal por onde essas unidades se articulam através de diversos fluxos. Segundo Mance, um princípio básico dessa noção de rede é que ela funciona como um sistema aberto que se auto-reproduz, isto é, como um sistema autopoiético. A ideia de rede que conecta grupos de um determinado movimento social, neste caso, mulheres praticantes de teatro, é a de que a articulação entre todos os movimentos deste tipo fortaleça cada movimento em particular pelos intercâmbios que passem a ocorrer entre eles e que tal fortalecimento venha a contribuir no surgimento de novos movimentos em outros lugares, passando a atuar em uma área muito maior do que a atingida pelo conjunto dos movimentos já organizados. (MANCE, 1999, p. 24)

- irrelevant; by a kind of spontaneous cooperative action the like of which we have never seen; which is so far from people's ideas of state structure or viable social structure that it seems to them like total anarchy - when what it really is, is very subtle forms of interrelation that do not follow some hierarchal pattern which is fundamentally patriarchal. The opposite to patriarchy is not matriarchy but fraternity, yet I think it's women who are going to have to break this spiral of power and find the trick of cooperation." GREER, Germaine. The Female Eunuch. Paladin, 1970. 
Quando falamos em rede certamente não nos referimos apenas a um desenho ou uma composição formal diagramada em um espaço plano. A disposição em rede não implica necessariamente em uma operação em rede. Mas é preciso operar em rede para existir como tal. Martinho afirma que

"a horizontalidade é uma espécie de exigência de um sistema com alto grau de empoderamento dos atores e é também o resultado necessário de um sistema desse tipo. As redes é que dão conta de articular - e de organizar, com métodos e metas - atores sociais autônomos, diferentes $e$ empoderados, que não admitem subordinação (o fundamento da estrutura hierárquica vertical), mas tão somente cooperação e coordenação. (MARTINHO, 2011, p. 6)

Segundo ele, a potencialização da capacidade de intervenção desses atores sociais, assim como a promoção de suas ações, dependeria da transformação efetiva desses coletivos em redes. E uma rede, tecida a partir das interseções de seus nós visíveis, ganha força e integridade justamente nos pontos onde aparentemente não há nada, nos espaços que se criam entre os pontos de coesão. Martinho salienta as características de plasticidade e dinamismo da rede, cuja configuração seria regida por mecanismos de auto-regulação.

Redes não tem centro, isto é, qualquer ponto da rede é um centro em potencial. Redes são entidades fluidas, indefinidas (num sentido deleuziano do termo), isto é, não-delimitadas, não-circunscritas e não-descritas conforme as taxionomias existentes (nisso as redes são coetâneas da realidade virtual, da androginia, das chamadas culturas híbridas e de outros fenômenos sociais pós-modernos). (MARTINHO, 2011, p. 2)

No livro "A teia da vida", o físico austríaco Fritjof Capra estabelece relações entre as redes presentes nos ecossistemas e as formas de organização humana. Segundo ele, há um padrão comum de organização que pode ser identificado em todos os organismos vivos cuja propriedade mais importante é a de ser um padrão de rede. Onde houver sistemas vivos, seus componentes estão arranjados à maneira de rede. "Sempre que olhamos para a vida, olhamos para redes" (CAPRA, 1996, p. 102). Ou seja, as redes seriam, segundo Capra, as formas mais orgânicas de organização, marcadas pela não-linearidade (ela se estende em todas as direções), pela realimentação (a possibilidade de um caminho cíclico que pode gerar um laço de realimentação ao longo do percurso) e pela auto-regulação (aprende com seus erros e os corrige). 


\section{Vínculos e espaços vazios: a busca do outro}

Em palestra proferida em Florianópolis ${ }^{3}$ sobre o legado e o desafio do Projeto Magdalena, a atriz Julia Varley ${ }^{4}$, co-fundadora do projeto e uma de suas integrantes mais atuantes, discorreu sobre uma imagem que utiliza para pensar o conceito de rede:

o que é uma rede? Uma rede tem linhas, fios, esses fios se cruzam. Os fios são as diferentes mulheres. Vocês escutaram algumas hoje, outras vocês viram nas fotografias, nos vídeos. [Os fios] são também os eventos, os festivais, os espetáculos, as oficinas, os livros, a documentação, os vídeos. Tem muita coisa que faz [com] que existam esses fios que se cruzam. o Projeto Magdalena é o espaço que se cria entre os fios. (...) Então [o Projeto Magdalena] é um espaço vazio, um espaço que cada uma tem que gerar, preencher com o que precisa colocar ali. (VARLEY, 2010).

A ocupação deste vazio do espaço (ou deste espaço vazio) que, segundo ela, existe entre os fios da Rede Magdalena, é determinante para a criação de vínculos e de ambiências criativas que possibilitem reunir tantas diferenças, tantas maneiras distintas de fazer teatro, a partir de idades, países e personalidades diferentes, gerando trabalhos cujo denominador comum não está nas opções éticas ou estéticas, mas no fato de serem feitos com precisão, rigor e refinamento estético.

A temática do rigor na criação artística foi amplamente discutida em uma mesa redonda intitulada "Solidariedade do rigor", realizada recentemente dentro do evento "The Magdalena Project@25 - Legacy and Challenge" [Projeto Magdalena@25 - Legado e Desafio] em comemoração aos 25 anos do projeto na cidade de Cardiff, no País de Gales. Entre outras questões, foi abordada a necessidade de criação de uma plataforma solidária para a apreciação crítica de trabalhos artísticos, buscando evitar simultaneamente a condescendência com a fragilidade e a atitude destrutiva para com o trabalho alheio. ou seja, admite-se que há uma forte carga de tensão na concepção e execução de trabalhos teatrais que configuram o universo do que Eugenio Barba chama de "terceiro teatro", nomenclatura eventualmente utilizada para identificar produções vinculadas à rede. Esta tensão está ligada fundamentalmente à necessidade de domínio do ofício e à busca incessante de resultados de alto nível de elaboração. Mas esta busca - e eventual cobrança - de rigor estaria permeada pela criação de um ambiente solidário, que investe na criação de vínculos como estratégia de organização.

3 A palestra intitulada Magdalena 25 anos: identificando o legado e o desafio foi proferida no Vértice Brasil 2010 - encontro e festival de teatro feito por mulheres, em 23 de julho de 2010, em Florianópolis.

4 Julia Varley, atriz integrante do grupo dinamarquês Odin Teatret, além de ter participado da fundação do Projeto em 1986, é diretora/coordenadora do Transit Festival, realizado periodicamente na Dinamarca, na sede do seu grupo, como parte dos eventos Magdalena. 0 Transit Festival está na sua sexta edição (a última ocorreu em 2009). 
Segundo Norval Baitello Jr., a necessidade de criação de vínculos para efetivar 0 processo comunicativo nos leva à busca do outro, do outro corpo, que nos projeta além de nós mesmos. Na criação de "ambientes de vínculos", desaparece o indivíduo e instala-se um "nó, apoiado por outros nós e entrecruzamentos", reduzindo a fragilidade da solidão humana em prol de entrelaçamentos que se dão a partir de corpos vivos (BAITELLO, 2008, p. 97-100). A Rede Magdalena parece levar às últimas conseqüências esta necessidade primordial de vinculação, presente na espécie humana desde 0 nascimento5, nos proporcionando um caminho para pensar as relações de alteridade e intersubjetividade na arte.

Uma experiência colaborativa considerada entre as mais significativas vivenciadas dentro do Projeto Magdalena é relatada pela atriz norueguesa Anne Erichsen, integrante do Grenland Friteater:

Em 1989, organizamos um laboratório na Noruega - 40 mulheres trabaIhando juntas durante 20 dias. Organizamos quatro grupos com uma diretora em cada um. Ao final, fizemos uma apresentação do espetáculo criado. Foi um grande desafio reunir mulheres tão diferentes trabalhando de formas tão distintas. Mas houve uma conexão muito intensa entre as pessoas que possibilitou que chegássemos a um resultado interessante (ERICHSEN, 2011).

No mês de julho de 2011, durante o Congresso Siete Caminos Teatrales / The Magdalena Project, promovido pela Fundação Cervantista na cidade de Guanajuato, México, dois espetáculos apresentados provocaram discussões e reflexões que nos ajudam a pensar estas questões. SITA é uma co-produção entre artistas mexicanas e cingapurenhas a partir do personagem hindu (Sita é a mulher de Rama, do célebre épico Ramayana), e tem como ponto de partida o treinamento das atrizes envolvidas: Elizabeth de Roza (Cingapura) tem domínio do Kalari Payatu', Eugenia Cano Puga (México) tem formação em Kathakali’. Ambas as disciplinas são originárias do sul da Índia e requerem forte treinamento físico (originalmente praticado apenas por homens) pautado na precisão e agilidade, além de extrema codificação gestual. 0 espetáculo foi concebido e preparado em cinco encontros presenciais em países distintos (Cuba, Dinamarca, Brasil, Índia e México), além de

50 psicólogo americano Donald Winnicott refere-se ao olhar da mãe como fator primário para a organização da nossa humanidade. Ao olhar o rosto da mãe, o bebê vê a si mesmo. "Quando olho, sou visto; logo, existo." Tem início ali a percepção, e a lenta e gradativa separação, entre um mundo subjetivo, interno, e um mundo objetivamente percebido a partir de elementos externos ao indivíduo (WINNICOTT, 1975, p. 157).

6 Kalari Payatu é uma arte marcial indiana, proveniente de Kerala, no sul da Índia, considerada precursora de todas as artes marciais desenvolvidas na região. 0 treinamento inclui pancadas, pontapés, agarramentos e técnicas com armamentos.

7 Kathakali é uma forma clássica de dança-teatro, proveniente de Kerala, no sul da Índia, cujos elementos estão estruturados de forma extremamente codificada, implicando em uma atuação amplamente estilizada do ator. 
inúmeros encontros virtuais. As atrizes tinham como propósito desenvolver um trabalho colaborativo através de um encontro entre duas culturas buscando pontos em comum. A partir de questões suscitadas pelo "estar em trânsito", pela busca do "entre" (o estado de in betweeness, segundo Roza) como um espaço de criação e descobertas, pelas tensões existentes entre tangibilidade e intangibilidade em seu processo criativo, as atrizes procuraram buscar "similaridades na diferença". Durante 0 processo, as atrizes confrontaram-se constantemente com a noção de liminaridade proposta por Victor Turner: o que há no espaço do entre? 0 que ocorre no in between?

A linguagem do corpo (o discurso gestual) funcionou nesse contexto como elemento de tradução intergestual e intercultural. Para Brook, o gesto seria o terreno de encontro universal entre atores de culturas diferentes. Assim, uma prática intercultural implicaria necessariamente em uma confrontação de gestualidades (BROOK apud PAVIS, 2008) 0 corpo seria, nesta perspectiva, o local do encontro intercultural.

0 trabalho foi construído a partir de uma situação de trânsito indefinido, encontrada em viagens, em jornadas, no espaço entre a partida e a chegada, a origem e o destino, o começo e o fim. Segundo as atrizes, um espaço transitório localizado em lounges, salas de espera, lobbies de hotel, em lugares onde "não estamos exatamente em casa. Ainda não chegamos. Saímos de casa, mas ainda não chegamos a uma nova casa. Então estamos no entre." (ABRAMOVIC apud PHELAN, 2004, p. 21, trad. nossa).

Num percurso distinto, mas com alguns pontos em comum, a performer Violeta Luna, mexicana radicada em São Francisco (EUA), criou a performance Apuntes sobre la Frontera, que integra a Trilogia da Fronteira, relacionada com os temas de migração, exílio e ilegalidade na fronteira entre México e Estados Unidos, e desenvolvida em parceria com o coletivo Secos y Mojados, sediado em São Francisco. Fortemente influenciada pela performance art, a atriz desenvolve sequências corporais em interação constante com a plateia, intercaladas com imagens em vídeo de forte carga política e social.

Violeta Luna apresenta uma imigrante que deixa seu país em busca de melhores condições de vida. Em suas malas, tanto as concretas quanto as poéticas, carrega o necessário para começar vida nova. Seu percurso é marcado pelo fato de haver cruzado "pro outro lado" e de ter uma consciência permanente do "aqui" e do "lá", do "antes" e do "depois". Assim, suas recordações e sua memória se tornam a base de seu passado e seu futuro e trazem a perspectiva de sua existência como imigrante, exilada, refugiada, ilegal, nômade. Como pano de fundo, a performer busca sua própria identidade em um ambiente híbrido e de contornos pouco definidos.

Nos dois trabalhos, encontramos uma prática permeada pela fusão entre múltiplas culturas, resultando em procedimentos criativos e modos de construção espetacular marcados por hibridismos, miscigenações e contaminações interculturais. 


\section{Por que um legado?}

Ao completar meio século de existência em plena efervescência, o Projeto Magdalena se depara com sua força e vitalidade crescentes, facilmente detectáveis através da amplitude da rede e da relevância das profissionais que a integram nos mais diversos países. Procurando projetar os próximos 25 anos, suas integrantes reunidas em Cardiff discutiram estratégias de sobrevivência, ao mesmo tempo em que fizeram um balanço de perdas e ganhos.

0 contexto do Projeto Magdalena tem sido fortemente marcado por experiências laboratoriais e colaborativas, além de um intenso compartilhamento de tradições teatrais e de experimentação estética. Historicamente, a perspectiva da troca sempre foi priorizada em detrimento da simples apresentação de espetáculos. 0s momentos de crise enfrentados pelo projeto, que não foram poucos, relacionados seja com a infra-estrutura organizacional seja com divergências ideológicas não só foram superados como serviram de alavanca para a revitalização da rede e para a superação de binômios instalados historicamente, como as noções de centro e periferia.

Ao optar pela periferia (geografica e esteticamente) como uma escolha ideológica e ética, a Rede Magdalena se propõe a negar velhos paradigmas - inclusive teatrais - para apostar no risco, no corpo que abandona a falsa segurança promovida pela verticalidade e transforma o desequilíbrio em energia, em desafio. A periferia torna-se então o local de exploração do novo, o local onde valores essenciais encontram ambiente propício para florescer.

As características dialógicas, que dizem respeito ao permanente diálogo, nem sempre simétrico e harmonioso, existente entre os diferentes discursos que configuram esta comunidade, a dispõem em um lugar onde a influência contínua do discurso do "outro" não só é permitida, mas é intensamente desejada, perseguida. Trata-se, acima de tudo, de uma pluralidade de vozes que coexistem em trabalho, em ação, e configuram esta densa experiência de alteridade.

Este lugar do "entre", entre dois corpos, duas instâncias vivas, duas culturas, é onde o processo de comunicação se estabelece e cria vínculos. Em Winnicott, este espaço potencial é o lugar da brincadeira - do viver criativo - e da experiência cultural. Ao investir na ocupação desse espaço, o Projeto Magdalena aposta no contato, no vínculo, e possibilita que a comunicação e o encontro aconteçam de maneira efetiva, trazendo uma contribuição original e significativa para a produção teatral contemporânea. 


\section{Referências Bibliográficas}

> BAITELLO JR., Norberto. Corpo e imagem. Comunicação, ambientes, vínculos. In: R0DRIGUES, Davi (org). Os valores e as atividades corporais. São Paulo: Summus, 2008.

> BARBA, Eugenio. Além das ilhas flutuantes. Campinas: Hucitec/Unicamp, 1991.

$>$ BASSNETT, Susan. Magdalena: International women's experimental theatre. Providence, USA: Berg Publishers Limited, 1989.

> CAPRA, F. A teia da vida. Ed. Cultrix: São Paulo, 1996.

> CASTELLS, Manuel. A sociedade em rede: a era da informação: economia, sociedade e cultura. São Paulo, vol. 1: Paz e Terra, 1999.

> ERICHSEN, Anne. The Magdalena Europe, Australasia, Taiwan. Cardiff, 2011. Palestra realizada no THE MAGDALENA PROJECT@25 em 19 ago. 2011.

> FRY, Chris. The way of Magdalena: a chronicle of the first ten years of the Magdalena Project. Holstebro, Denmark: Odin Teatret Forlags / Open Page Publications, 2007.

> GREENHALGH, Jillian. Origem do Projeto Magdalena. Florianópolis, 2008. Palestra realizada no VÉRTICE BRASIL em 15 jul. 2008.

> GREENHALGH, Jillian. Guanajuato, 2011. Palestra realizada no CAMINOS TEATRALES 7 em 17 jul. 2011.

> GREER, Germaine. The Female Eunuch. Paladin, 1970.

> MANCE, Euclides André. A revolução das redes. São Paulo: Vozes, 1999.

> MARTINHO, Cássio. Algumas palavras sobre rede. Disponível em: <www.observatoriosocial.org.br/.../Algumas_palavras_sobre_redes.pd... Acesso em: 6 jun. 2011.

> PHELAN, Peggy. On seeing the invisible. Marina Abramovic's The house with the ocean view. In: HEATHFIELD, Adrian. Live: art and performance. Routledge, 2004.

$>$ PAVIS, Patrice. 0 teatro no cruzamento de culturas. São Paulo: Perspectiva, 2008.

> VARLEY, Julia. Magdalena 25 anos: identificando o legado e o desafio. Florianópolis, 2010. Palestra realizada no VÉRTICE BRASIL 2010 em 23 jul. 2010.

> WHITAKER, Francisco. Rede. Uma estrutura alternativa de organização. Artigo publicado na Revista Mutações Sociais. CEDAC, Rio de Janeiro, março/abril/maio, 1993.

> WINNICOTT, Donald. o brincar e a realidade. Trad. José Octavio de Aguiar Abreu e Vanede Nobre. Rio de Janeiro: Imago, 1975.

Marisa de Souza Naspolini, doutoranda PPGT - UDESC marisanaspolini@floripa.com.br 